years, but we would like to comment on certain points he raises.

Dosage.-Although we have stated ${ }^{1}$ that intravenous injection does not prevent nausea, it can be used effectively, and without severe nausea or vomiting, in patients who are totally unable to tolerate the oral treatment as out-patients. To avoid unnecessary prolongation of hospitalization our schedule of intravenous therapy for reticuloses has been to give $3.75 \mathrm{~g}$. of the drug within seven days, and for solid tumours $5.75 \mathrm{~g}$. in 11 days. This schedule is useful where a quick result is desired.

Nausea.-It has been stated ${ }^{2}$ that methylhydrazine therapy should not be combined with chlorpromazine or other phenothiazines. Potentiation of the effect of chlorpromazine has occurred in our series, but we agree with Todd that small doses of such anti-emetics are very useful.

Toxicity.-One patient developed an exfoliative dermatitis which responded to withdrawal of methylhydrazine and treatment with steroids. No epilation occurred in our series of 40 cases, and indeed one patient epilated with cyclophosphamide regrew her hair whilst receiving full doses, of methylhydrazine.

Combination Therapy.-An impression has been gained (but so far it is not proved) that after an interval, peculiar to that patient, resistance to continued treatment develops and that further prolongation of maintenance therapy is unnecessary. A change to another type of cytotoxic then often results in a further remission. This has occurred dramatically with the sequence cyclophosphamide - methylhydrazine - cyclophos phamide in cases of carcinoma of the bronchus and myelomatosis. Such "switching " does not appear to be so effective if one allows a long interval, more than a week or two, between the treatments. This alternation between alkylating agents and methylhydrazine and possibly vinblastine requires further study.

We agree with Dr. Todd that methylhydrazine has a place in the palliation of Hodgkin's disease and other reticuloses, and we would encourage further study of its use in sequential treatment with alkylating agents in solid tumours.-We are, etc.,

\section{K. Sicher.}

T. W. BACKHOUSE.

Department of Radiotherapy,

Coventry and Warwickshire Hospital, Coventry.

\section{REFERENGBS}

1 Sicher, K., and Backhouse, T. W., Lancet, 1963, Gerhartz, H., in Chemotherapy of Cancer, edited
by Pl. A. Plattner, p. 215, 1964 . Elsevier,
Amsterdam.

\section{Plasma Transfusions in Haemophilia}

SIR,-Mr. P. H. Smith's report (30 January, p. 296) of a case of haemophilia submitted to splenectomy is of considerable interest, but some of his conclusions regarding management of haemophilia during surgery may be questioned.

The view that plasma therapy alone is of no value in the management of major surgery in haemophilia does not accord with experience in our laboratory. We have treated cases subjected to appendicectomy, lamin- ectomy, evacuation of a subdural haematoma, and arthrodesis of an ankle ${ }^{1}$ as well as correction of a strabismus, removal of osteophytes and loose bodies in a knee, and lengthening of the Achilles tendon (unpublished cases) with fresh or frozen fresh-plasma transfusions. Satisfactory haemostasis with a normal rate of wound healing post-operatively and adequate. levels of antihaemophilic globulin (A.H.G.) (25-30\%) were achieved with plasma doses of $30 \mathrm{ml} . / \mathrm{kg}$. body weight per day in all cases except one. The latter was the case submitted to arthrodesis of the ankle, and was complicated by a staphylococcal septicaemia, as a result of which inadequate doses of plasma were given.

Human concentrates of A.H.G. were not readily available to us, and we were reluctant to use animal concentrates except as a last resort. Experience with fresh or frozen fresh plasma led us to believe that adequate levels of A.H.G. could be achieved provided the plasma was correctly processed prior to transfusion ${ }^{1}$ and adequate doses were given. Most cases, including children, have tolerated doses of $30 \mathrm{ml} . / \mathrm{kg}$. body weight per day for periods up to eight days very well, although one case did show signs of circulatory overload. Reduction of the dose to $25 \mathrm{ml} . / \mathrm{kg}$., together with diuretic therapy and salt restriction, enabled us to continue therapy in this case.

In Mr. Smith's case the dosage of plasma in terms of $\mathrm{ml}$. per $\mathrm{kg}$. body weight per day is not given. Furthermore, the A.H.G. content of the transfused plasma is not stated. The failure of the plasma therapy may therefore have been due to inadequate dosage, either because the volume given was inadequate or because the plasma-A.H.G. content was low.

Although it is true that human A.H.G. concentrates have a number of advantages over plasma transfusions, the concentrates are not yet freely available in all parts of the world. Animal concentrates at present are limited in their use by the danger of anaphylactic reactions, and, although this problem may well be overcome in the future, it is, I believe, generally agreed that at present these preparations should be reserved for lifethreatening situations. For these reasons our policy has been to treat all cases submitted to surgery with plasma transfusions in the first instance, and to keep a reserve stock of human and animal concentrates available for those cases which fail to respond to the plasma. To date we have been fortunate and have not needed to use concentrates. - I am, etc.,

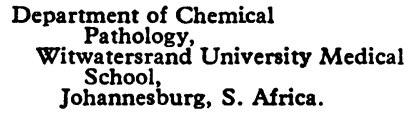

REFERENCE

1 Bradlow, B. A., Ellis, B. C., and Abrahams, O. L., Med. Proc., 1960, 6, 2s3.

\section{Combining the Antidepressant Drugs}

SIR,_Having read Dr. W. W. Sargant's recent plea (23 January, p. 251) for reports of reactions to the combination of imipramine and phenelzine, I wish to advise of the following case in which a near fatal reaction occurred, and in which there is in my mind little doubt as to the cause of the crisis.

A 29-year-old woman was admitted to the Royal Perth Hospital on 15 March 1962 with an exacerbation of anorexia, insomnia, nervousness, headaches, depression, and abdominal pain. She had amenorrhoea of six years' duration and had been diagnosed as suffering from anorexia nervosa, macrocytic anaemia, and a hiatus hernia Physical examination revealed a thin melancholy girl complaining of headache. Her blood-pressure was $105 / 70$ and there were no significant findings elsewhere. Her weight was 6 st. 1 lb. (38 kg.)

Phenelzine (Nardil) $15 \mathrm{mg}$. three times a day had been given earlier whilst an out-patient, and this was continued. Drugs given other than the antidepressants were thioridazine $75 \mathrm{mg}$. three times a day, and oxyphencyclimine hydrochloride $5 \mathrm{mg}$. three times a day. As there was no improvement apparent after a month, a course of intramuscular imipramine (Tofranil) was advised, and this was commenced at a dose of $25 \mathrm{mg}$. three times a day. Phenelzine was continued as before. Up to this point the patient's general condition had been quite static. Fifteen hours later, when two doses had been given, she was noted to be fully conscious and rational as usual, but her hands were cold and sweating. Six hours. later, after one further injection, she was found to be delirious and obviously febrile even to touch. Temperature was then recorded at $42^{\circ} \mathrm{C}$., while a blood-pressure reading gave a systolic figure of $60 \mathrm{~mm}$. $\mathrm{Hg}$ and a pulse rate around 160 per min. There was also extreme rigidity of the whole body, the feet being plantar-flexed to the extreme.

She was given $100 \mathrm{mg}$. intravenous hydrocortisone and the blood-pressure elevated thereafter with Levophed (noradrenaline acid tartrate) by intravenous drip. Cooling was induced with spirit bathing, fans, and ice. Six hours later the blood-pressure remained steady and the temperature appeared under control. Marked muscle spasm was still evident. Another two and a half hours later consciousness was regained.

Her subsequent course was uneventful. She was submitted to leucotomy several weeks later and since then has made a dramatic recovery.

-I am, etc.,

Royal Perth Hospital, Western Australia.

N. F. Hills.

\section{Diet and Dental Disease}

SIR,-As a doctor working in a remote and very poor part of Tanzania I read the letters on "Diet and Dental Disease" (21 November, p. 1332) with interest. The diet around here, which is just above subsistence level, is predominantly cereal. The absence of coronary thrombosis, peptic ulcer, diabetes, ulcerative colitis, diverticulitis, piles, and varicose veins is noticeable, but I should like to eomment on dental disease. Bush-school examinations plus out-patient work reveal that on the whole the local teeth are remarkably free of caries. However, as one has to do one's own dentistry here the severe type of caries which does appear in a minority is very striking. The teeth are rotten and often parts of them squeeze between the forceps blades like cheese. I have wondered is this caries linked with the locally prevalent habit of chewing cassava, consisting as it does mainuy of carbohydrates?

Commenting on a point raised in $\mathrm{Mr}$. $\mathrm{H}$. Dodd's letter, may I say that the incidence of hernia in Southern Tanganyika is very high.-I am, etc.,

RICHARD DREAPER.

Mnero Mission Hospital, 